\section{THE VALUE OF DESIGN PESE}

11TH EUROPEAN ACADEMY OF DESIGN CONFERENCE

APRIL 22-242015

PARIS DESCARTES UNIVERSITY INSTITUTE OF PSYCHOLOGY

BOULOGNE BILLANCOURT FRANCE

CONFERENCE ORGANIZERS:

PARIS DESCARTES UNIVERSITY PARIS SORBONNE UNIVERSITY PARIS COLLEGE OF ART ISTEC PARIS

\title{
RESILIENT CO-CREATION OF VALUE WITH THE CONSUMER SERVICE DESIGN DERIVED FORMS OF VALUE AS STRATEGIES FOR SUBVERSION.
}

\author{
Telalbasic, I da
}

only.type.ida@gmail.com

\author{
Department for Products, Services and \\ Strategies, Politecnico di Milano
}

only.type.ida@gmail.com

\begin{abstract}
This paper represents the process of an on-going participatory action research project within a city affected by the socio-economic crisis. The focus of the research is to explore the possibilities of transforming idle capacity of skilled professionals into job opportunities through service design and defining strategies for designing a new value creation system between members in a community. The existing complementary currency models serve as an inspiration and foundation for conducting the research in collaborative and creative spaces, using a bottom-up approach in designing this service with the potential users in order to create value for that community. This could be achieved by giving shape to a service with its evidences as a framework to adapt to current conditions in peer-to-peer interactions. If a successful long-term and not only crisis-driven model could be designed, prototyped and globally replicated, based on debt-credit system and knowledge economy with enormous benefits of access to products and services, then it could enhance economic efficiency and distribute social capital while promoting new forms of entrepreneurship.
\end{abstract}

Keywords: resilience, complementary currency systems, co-working spaces, cocreation of value, collaborative services

\section{I NTRODUCTI ON}

If we understand that Service Design is "an approach that combines different methods and tools from various disciplines, being a new way of thinking as opposed to a new stand-alone academic discipline" (Stickdorn \& Schneider, 2012), we are then forced to explore the farthest opportunities that this discipline can provide.

Especially if the current economic crisis is "a crisis of the real economy, of an old form of production and consumption" (Murray, 2009) and as foreseen by Schumpeter "what is needed is a program of more profound structural change, of a radical transformation of infrastructures and institutions that will be the precondition for a new, qualitatively different period of growth" (Murray, 2009).

The socio-economic crisis has created circumstances that have as a consequence created high unemployment. This is important because young professionals, social entrepreneurs and start-uppers are affected and are neither able to operate and develop their businesses nor offer their skills and competences on the market. Ultimately we need to respond to this pressing social issue of our time.

The theoretical framework encompasses disciplines such as sociology with 'wicked problems' (Buchanan, 1992) such as unemployment, including topics 


\section{THE VALUE OF DESIGN BESE}

11TH EUROPEAN ACADEMY OF DESIGN CONFERENCE

APRIL 22-242015

PARIS DESCARTES UNIVERSITY INSTITUTE OF PSYCHOLOGY

BOULOGNE BILLANCOURT FRANCE

CONFERENCE ORGANIZERS:

PARIS DESCARTES UNIVERSITY PARIS SORBONNE UNIVERSITY PARIS COLLEGE OF ART ISTEC PARIS
Resilient co-creation of value with the consumer. Service design derived forms of value as strategies for subversion.

Telalbasic, Ida such as the age of access, knowledge transfer and virtual-real interactions. Within the discipline of economics, topics that are of most interest to this research are knowledge and social economy, collaborative consumption models, self-entrepreneurship, new business models, credit-debt systems and in this case complementary currencies as metaphors for value.

Service design includes the activity of planning and organising people, infrastructure, communication and material components of a service in order to improve its quality and the interaction between the service provider and the customer (B. Mager, 2008). Concerning social innovation, Murray (2009) states that there is "a practical action underway to develop the field with more solid evidence, methods, capacity - for everything from the diagnosis of problems to the design of solutions, prototyping, testing, sustaining and diffusing". Botsman $\&$ Rogers (2011) have defined the importance of 'collaborative consumption' as the ability for people to "realize the enormous benefits of access to products/services over ownership and at the same time save money, space and time, make new friends and become active citizens once again".

The different emerging service models that are important to understand and being used everyday by people, include bartering, lending/borrowing, renting, gifting and swapping that are being redefined through technology and peer communities. We can definitely recognize a trend in the evolution of co-working and creative spaces, such as the hubs, fab-labs, living Labs, incubators etc. where people are interacting with each other in order to co-work, exchange and create ideas together. Especially if we deeply analyse the existing different sharing modalities and their specific characteristics, there is a sharing of living spaces such as co-housing, sharing of tools, skills and infrastructure. There seems to be an opportunity for collaborative consumption systems to become the right tool in finding alternative models for these types of exchanges.

Complementary currencies are one way to strengthen the relationships within a city and I am assuming that this can be applied in peer-to-peer communities, targeting the professional environment of skilled individuals who have the competences and know-how but are currently unemployed.

\section{FOCUS FI ELD}

The intention of this participatory action research is to explore the strategies of designing a new value creation system between members in a community. The goal is not to only apply an existing complementary currency model as it is into collaborative spaces, but to use a bottom-up approach in designing this service with the potential users in order to create value for that community. The task at hand requires choreography of solutions that are not yet available; by observing, interpreting needs and behaviours and ultimately transforming them into potential future services.

"Complementary currency is a standardized unit or medium of exchange that circulates in parallel to conventional money." (Lietaer, 2002). We can also see their importance by the forms and shapes they can have as Kalinowksi (2011) claims:

"Parallel currencies play a critical role in the current wave of social innovation. They can assume different forms - local currencies, time-currencies, local 


\section{THE VALUE OF DESIGN PESE}

11TH EUROPEAN ACADEMY OF DESIGN CONFERENCE

APRIL 22-242015

PARIS DESCARTES UNIVERSITY INSTITUTE OF PSYCHOLOGY

BOULOGNE BILLANCOURT FRANCE

CONFERENCE ORGANIZERS:

PARIS DESCARTES UNIVERSITY PARIS SORBONNE UNIVERSITY PARIS COLLEGE OF ART ISTEC PARIS
Resilient co-creation of value with the consumer. Service design derived forms of value as strategies for subversion.

Telalbasic, Ida exchange systems, inter-company credit systems and can be implemented in a wide variety of ways: as mutual funds, as mechanism for territorial or social cohesion etc."

Why do we speak of a complementary currency? Due to the economic crisis, there is a deficit of cash flow and we are forced to find alternative models for sustaining our activities. The spaces where this can happen can be both physical and digital spaces where the convergence of people and activities are based on a common need for interaction. How do we put people together with their latent needs to exchange skills/competences with possibilities that have not yet been identified?

By applying a design-led approach to social innovation, what needs to be designed is a new service model within cities affected by the socio-economic crisis and to explore collaborative and creative spaces by the means of decentralized exchange. The design-led approach considers the process of visualisation, exploration, generation and evaluation of approaches to design an old concept of bartering, using an alternative medium for exchange that is supported by technology and made accessible to communities that could benefit from a such a service model. The specific aims of this service would be the creation of relationships, qualities and realization of needs through a complementary currency where the word "currency" acts as a metaphor for social value creation and evaluation. The newly created value acts as a means for exchange in an informal economy to take place in a defined system.

For a generation of highly-skilled individuals who are not able to find work, or provide their goods and services in the standard forms of market places, complementary currency systems seemed to have a high potential in involving these target groups into newly structured systems that enable a new type of exchange of their knowledge, know-how, expertise and experience. There are a huge number of complementary currency systems globally, but the ones that are interesting for us are the ones with a social purpose, not facilitating only commercial transactions but aiming to address specific social issues.

The four reasons why complementary currency exists are:

1) Enhance economic efficiency while promoting new forms of entrepreneurship and organizing economic activity in areas suffering from existence of a unique monetary instrument (Lang, 1994),

2) Create and distribute social capital, developing trust-based relationships, promoting co-operation and strengthening existing networks (North, 2001),

3) Support community development for example - the relocation of economic activity in the perspective of self-sustainability (Pacione, 1997),

4) Organize emerging forms of non-profit activity and public welfare based on self-help and mutual assistance (Douthwaite, 1999).

The conceptual direction of this research is a 'matrifocal' one, since 'patriarchal' societies in history have had the tendency to impose a monopoly of a single currency, hierarchically issued, naturally scarce or artificially kept scarce, and with positive interest rates (B. Lietaer, 2010). "Patriarchal" societies have been positive primarily for the enabling capacity they provided for the Industrial 


\section{THE VALUE OF DESIGN

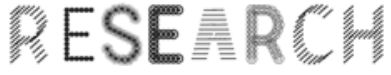

11TH EUROPEAN ACADEMY OF DESIGN CONFERENCE

APRIL 22-242015

PARIS DESCARTES UNIVERSITY INSTITUTE OF PSYCHOLOGY

BOULOGNE BILLANCOURT FRANCE

CONFERENCE ORGANIZERS:

PARIS DESCARTES UNIVERSITY PARIS SORBONNE UNIVERSITY PARIS COLLEGE OF ART ISTEC PARIS
Resilient co-creation of value with the consumer. Service design derived forms of value as strategies for subversion.

Telalbasic, Ida
Revolution as were characterized by great booms but on the other hand, also by great busts that have created instable economies. The negative aspect of such a society is also determined by a concentration of wealth that ultimately destroys communities and makes it quite incompatible with the gift economy.

On the other hand, "matrifocal" societies have existed for a long time as well, being economically very stable for centuries and are mainly defined as possessing a dual currency system. They are usually a different type of currency for local exchange that is bottom-up and aims to build and sustain communities as well as bring general wellbeing for everyone. The only negative aspect of this type of society is that it can only be used among people who know each other.

\section{CASE STUDI ES}

Since 1970, the International Monetary Fund defined hundreds of bank crashes and monetary collapses that clearly demonstrate an instable economic system. New forms of innovation can be closely observed through emerging practices that demonstrate a new set of existing behaviours as a way to address emerging social and economic problems. It is these types of self-organisations, created out of necessity, within local communities, and with the help of governing bodies in some cases, that as an asset provide a rich source of inspiring solutions.

The 'WIR Bank' from Switzerland is the most famous example of a system created before World War II and it still maintains the balance of the Swiss economy today. It was the first official complementary currency, creating jobs for small-to-medium enterprises to act as business-to-business transaction currencies. $1 / 4$ of all businesses use WIR currency, since it is stable and uses the mutual credit equivalency ( $1 \mathrm{WIR}=1$ Swiss Franc). The demand for WIR decreases in periods of growth and increases in periods of economic crisis. It also clearly demonstrates that exchanges that build communities without money are possible even on a large scale and can be lasting entities.

'Bristol Pound' is an example of a community currency, already implemented and functioning in the town of Bristol, U.K. The currency was initiated by citizens in order to have more control of where their money goes and make sure that it remains and circulates only within that city. If businesses or individual sellers accept this currency, they have more clients that are ready to pay for their services with this new complementary currency. Another important motivation for using this currency is that citizens get more value when they convert pounds into euros ( 100 euros $=110$ Brixton Pounds). There have been concerns on whether or not this could be a threat to the national economy. However the local authorities see this as a positive support for local traders since the currencies remains within the city and as a results, taxes can also be paid in this currency. 


\section{THE VALUE OF DESIGN PESE}

11TH EUROPEAN ACADEMY OF DESIGN CONFERENCE

APRIL 22-24 2015

PARIS DESCARTES UNIVERSITY INSTITUTE OF PSYCHOLOGY

BOULOGNE BILLANCOURT FRANCE

CONFERENCE ORGANIZERS:

PARIS DESCARTES UNIVERSITY PARIS SORBONNE UNIVERSITY PARIS COLLEGE OF ART ISTEC PARIS
Resilient co-creation of value with the consumer. Service design derived forms of value as strategies for subversion.

Telalbasic, Ida

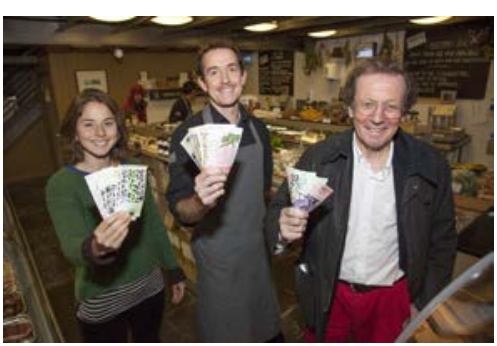

Figure 1. Sarah Forrester-Wilson from the Bristol Pound, Jo Wheatcroft, owner of the Source Food Hall and Cafe, and Mayor George Ferguson - http://www.bristol.gov.uk

Ultimately the spending habits of citizens change because they frequent the places that accept this currency and payments are possible with the following methods:

1) SMS

2) Electronic payment

3) APPs on mobile phones

4) Paper money (designs proposals are provided by citizens themselves with symbols that for them best represent the city of Bristol as in Fig.2).

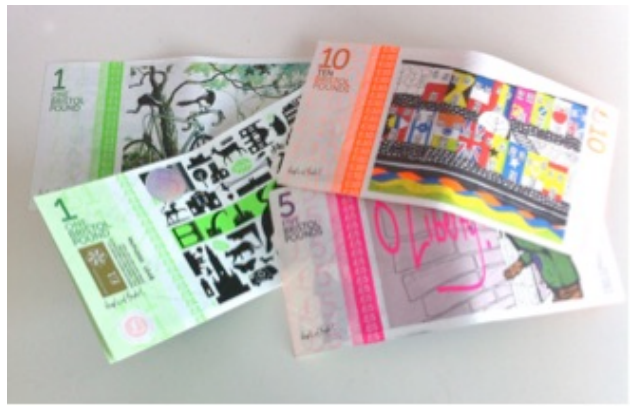

Figure 2. The Bristol Pound Notes

http://www.oisebristol.me/2012/09/25/by-virtue-and-industry/bristol-pound/

The WAT system in Japan is a type of circulating IOU (I Owe You) system between small businesses, their suppliers, and others who agree to accept the notes within the community. In the WAT system, the business uses a WAT ticket to pay their supplier; it is a form of ticket that states the amount owed, business who issued it with their signature (many stores in Japan use a special stamp) and whom it is being issued to. The supplier can then use the WAT to pay someone else, writing his name on the back of the note and the name recipient and the next recipient can do exactly the same thing. The note circulates in this way, adding names, until it finally reaches the original issuer, who accepts it at face value for goods or services and destroys the note. 


\section{THE VALUE OF DESIGN CESE}

11TH EUROPEAN ACADEMY OF DESIGN CONFERENCE

APRIL 22-242015

PARIS DESCARTES UNIVERSITY INSTITUTE OF PSYCHOLOGY

BOULOGNE BILLANCOURT FRANCE

CONFERENCE ORGANIZERS:

PARIS DESCARTES UNIVERSITY PARIS SORBONNE UNIVERSITY PARIS COLLEGE OF ART ISTEC PARIS
Resilient co-creation of value with the consumer. Service design derived forms of value as strategies for subversion.

Telalbasic, Ida

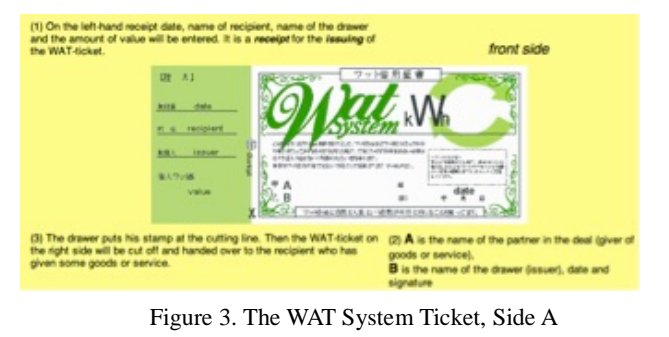

http://www.imaginationforpeople.org/en/project/wat-complementary-currency/

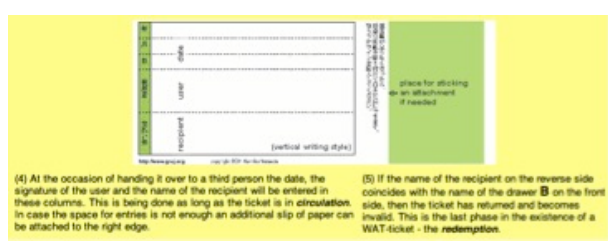

Figure 4. The WAT System Ticket, Side B

http://www.imaginationforpeople.org/en/project/wat-complementary-currency/

What is innovative about this system is that it is directly peer-to-peer; there is no central authority or administration that runs the currency. The trust in the WAT depends on trust within the community and that the original issuer will honour the note. Anybody willing to accept a WAT note is automatically a participant in the system. It is a system of exchange that allows for the free circulation of goods and services without using any money. The tickets are more than just an alternative currency because the practice of adding the participants' names to the ticket itself when it is exchanged means that their circulation creates the community. The more the ticket circulates before it is destroyed, the more a recipient can see how people have trusted the note and are willing to value it and pass it on. This means that the tickets themselves create the community; each participant adding their name adds to the ring of trust. Its limitations are that participants whose reputation is unknown are unlikely to be accepted as original WAT issuers, but as they participate and accept the notes and gain positive reputations, they are able to gain trust within the system.

If we take a look at some examples between developing and developed context, we can notice that the 'developing' status with regards to developing economies manifests diverse strengths within economic empowerment of the poor through permanent access to credit. One well-known practice is 'Grameen Bank' in Bangladesh (founded by Muhammad Yunus who received a Nobel Peace prize for his work in 2006) that demonstrates the potential of a microfinance contemporary banking phenomenon. Small loans provide the means for individuals in poverty to start small enterprises or agricultural initiatives and this has proven to work best when remains within small groups of individuals with common goals and backgrounds. 


\section{THE VALUE OF DESIGN PESE}

11TH EUROPEAN ACADEMY OF DESIGN CONFERENCE

APRIL 22-242015

PARIS DESCARTES UNIVERSITY INSTITUTE OF PSYCHOLOGY

BOULOGNE BILLANCOURT

FRANCE

CONFERENCE ORGANIZERS:

PARIS DESCARTES UNIVERSITY PARIS SORBONNE UNIVERSITY PARIS COLLEGE OF ART ISTEC PARIS
Resilient co-creation of value with the consumer. Service design derived forms of value as strategies for subversion.

Telalbasic, Ida

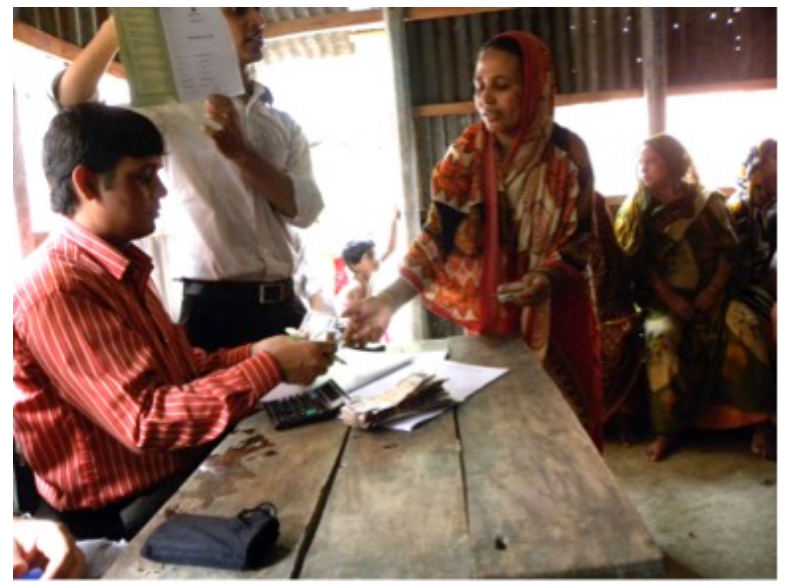

Figure 5. Grameen Bank borrowers attend a weekly center meeting to make loan repayments http://www.sowestimeast.wordpress.com

A common challenge between developed and developing contexts can be seen through practices that create behavioural change through reward. In a poor immigrant neighbourhood in Gent, Belgium, the government has applied complementary currencies as a tool where citizens can earn credits by sowing seeds and collecting litter in the public areas. The citizens are also given small plots of land as gardening space that they usually lack by living in low-cost apartments. The 'Torekes' currency that they receive for their work entitles them to buy low energy bulbs, groceries, movie tickets etc. at discounted prices. This example shows the impact of a system that provides more results for the same euro budget invested by the government for setting this system into place. The advantages of this system are benefits for all actors involved including the social value that it brings to the citizens, the government and the community in general. This is also one example where the design of the currency is not the sole purpose for diverse activities, but it serves as an enabler for this system to work. It supports the activities among the diverse actors and acts as a connector and provider for the circulation of goods, services, benefits etc.

Local residents in Kongowea, Kenya share the same values since the community currency encourages trade to remain within the neighbourhood, injecting capital into the local economy by allowing residents to care for and sustain their environment. This approach addresses residents in both contexts that are usually strapped financially and often fall to the sidelines in standard premium systems.

Another two practices that find mutual inspiration are the 'Bangla-Pesa' network in Kenya and 'Sardex' circuit of commercial credit in Italy. The two systems facilitate the exchange of goods and services, encouraging responsibility and building trust within the network. The 'Sardex' 'euroless' market constructs a circuit where no actors gain more money that they put in. This market allows firms to continue operating by circulating capital. It does not provide initial capital, but enables small to large businesses in Sardinia to trade goods and services in a matter that is sustainable, counter cycle and fosters social cohesion. 


\section{THE VALUE OF DESIGN PESE}

11TH EUROPEAN ACADEMY OF DESIGN CONFERENCE

APRIL 22-242015

PARIS DESCARTES UNIVERSITY INSTITUTE OF PSYCHOLOGY

BOULOGNE BILLANCOURT FRANCE

CONFERENCE ORGANIZERS:

PARIS DESCARTES UNIVERSITY PARIS SORBONNE UNIVERSITY PARIS COLLEGE OF ART ISTEC PARIS
Resilient co-creation of value with the consumer. Service design derived forms of value as strategies for subversion.

Telalbasic, Ida

Among the many disruptive practices that can be found in developing but uneven growth economies, are community development banks in Brazil, such as the 'Palmas Bank'. They aim to overcome extreme poverty and unemployment by developing a solidarity economy (an economy driven by common community betterment instead of making profits). The 'Red Global de Trueque' in Argentina is a reciprocal barter network, with an ecological focus in training people to practice sustainability by utilizing barter as an environmentally friendly consumption model without using money. This network encourages members to think of themselves as 'prosumers', stressing equality among citizens through the created exchanges. Both of these examples demonstrate prevailing solutions as a series of sustainable paradigm shifts to existing socio-economic challenges and thus reorganizing the behaviour patterns within the society as a whole.

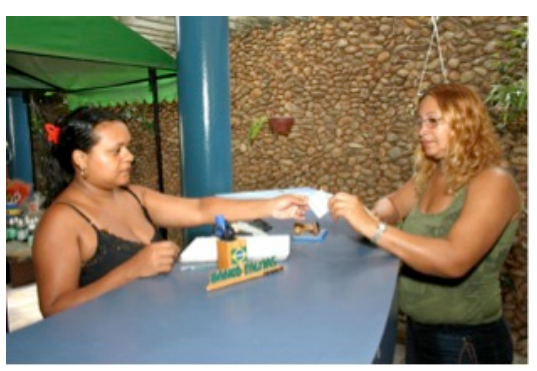

Figure 6. Banco Palmas, Brazil

http://www.changemakers.com

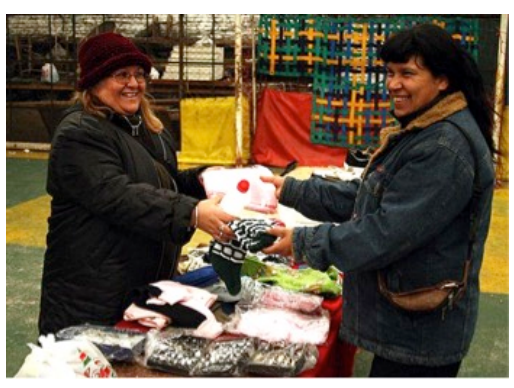

Figure 7. Red Global de Trueque, Argentina

http://www.lanacion.com.ar

The case studies illustrated that due to the nature and/or main causes of the global crisis in the different contexts in which it has emerged, it is clearly difficult to transnationally replicate an existing model into another context. One key question is what is the specific need that the application of a new complementary value creation system should fulfil? We can see that in the developed contexts, such as with the cases of 'Bristol', U.K., 'Sardex', Italy and 'WAT', Japan, all demonstrate a need for economic benefit, local and/or individual empowerment, enhancing collaboration and using existing local resources. Cases such as 'Palmas Bank', Brazil, 'Bangla-Pesa', Kenya and “Grameen Bank', Bangladesh all show the need for financial inclusion, building stronger community ties, trust and capacity building. 


\section{THE VALUE OF DESIGN BESE}

11TH EUROPEAN ACADEMY OF DESIGN CONFERENCE

APRIL 22-242015

PARIS DESCARTES UNIVERSITY INSTITUTE OF PSYCHOLOGY

BOULOGNE BILLANCOURT FRANCE

CONFERENCE ORGANIZERS:

PARIS DESCARTES UNIVERSITY PARIS SORBONNE UNIVERSITY PARIS COLLEGE OF ART ISTEC PARIS
Resilient co-creation of value with the consumer. Service design derived forms of value as strategies for subversion.

Telalbasic, Ida

\section{SCOPE AND METHODS OF RESEARCH}

This paper introduces research conducted with the aim to develop new insights about the potential value creation mechanism that could potentially exist in collaborative and creative spaces. The research project focuses on several key issues surrounding the nature of exchange mechanisms and value creation typologies. The objectives were to:

1) To investigate the peer-to-peer evaluation of knowledge as social capital that may be circulated within a well-trusted network.

2) To ensure mechanisms that guarantee reliability and accomplishment of tasks between members in a network.

3) To systematically make transparent the peer-to-peer transactions of debt and credit within the system.

The specific aim of the research is to transform idle capacity of skilled individuals into opportunities by giving shape to a service with its evidences as a framework to adapt to current conditions in peer-to-peer interactions. The creation of a new service model will have the potential to be applied in a broader perspective to horizontal networking that includes so-called 'glocal' concepts of small, local and open innovation that has the possibility to be replicated and scaled up globally.

The research methodology was conducted as a participatory action research project that followed parallel iterative design processes between the theoretical interpretations and the achieved implementation. The process of understanding how an existing co-working community interacts and collaborates was conducted through surveys and semi-structured interviews. Both research strategies surrounded key questions: the affects of the economic crisis and the way social entrepreneurs work; how the exchanges occur formally and informally; collaboration on national and international scale; potential of applying a new value exchange mechanism within the existing community.

The case studies analysis resulted in a matrix with the following typologies:

- Initiation of currency (community, individual, government and business);

- Interaction of actors (peer-to-peer, business-to-business, combination of both);

- $\quad$ Structure of system (centralized, de-centralized);

- System application (open, closed) and sector of operation (public, private).

The centralized currency systems distribute and/or monitor currency transactions through a central source that dictates the systems flows according to prior-set criteria. The de-centralized model has ownership, management and responsibility shared among community members. The open system means that it may have the potential to be replicated and scaled up in other locations, while the close system model targets a bounded and specific geographic area.

The methodology included the cases study analysis of exchange mechanisms around the world, both in developing and developed contexts, identifying the main drivers for co-creating value and understanding patterns in behaviour based on trust that is the main connector for those networks. 


\section{THE VALUE OF DESIGN BESE}

11TH EUROPEAN ACADEMY OF DESIGN CONFERENCE

APRIL 22-242015

PARIS DESCARTES UNIVERSITY INSTITUTE OF PSYCHOLOGY

BOULOGNE BILLANCOURT FRANCE

CONFERENCE ORGANIZERS:

PARIS DESCARTES UNIVERSITY PARIS SORBONNE UNIVERSITY PARIS COLLEGE OF ART ISTEC PARIS
Resilient co-creation of value with the consumer. Service design derived forms of value as strategies for subversion.

Telalbasic, Ida
The field research included a traditional method to design research, using interviews to directly contact founders and hosts of 'ImpactHUBs' around the world. Twenty-five semi-structured interviews were conducted, targeting and collecting attitudinal and qualitative forms of content, having a self-reporting role as a researcher. This method was used for the purpose of early exploration and as generative frames for the next concept generation phase. This global brand of co-working spaces acts as a part innovation lab, part business incubator, and part community centre. The members are offered a unique ecosystem of resources, inspiration, and collaboration opportunities to grow impact within their cities. It attracts social entrepreneurs and social innovators, such as start-uppers and young professionals, seeking to develop their own businesses through a highly valued network.

\section{RESEARCH FI NDI NGS}

The interviewees provided useful insight on how collaborations occur on local levels and that there is a need for a structured system for obtaining services from the community, especially with the scaling potential for international collaboration.

The results showed that the profiles could also include soft skills of members for increased self-reflection and this would widely contribute to the 'needs/offer' matching system. The profiles could be divided into three main categories:

1. Skills you would like to gift because you enjoy doing them

2. Skills you would like to swap by using time as a measure unit

3. Skills you would like to sell since you have worked hard to achieve them. A reciprocal rating system could give visibility to both members of the interaction by evaluating both the result of the work and the conditions created for the work to be completed. With reference to time-banking principles, the unit of measurement could be time or the achieved result, regardless of the time needed for the realisation of a certain task. The main issue concerns not the exchange model itself but the conditions in which a negotiation is accepted and both parties involved are happy with the result. This result could be measured with parameters of time and completed task.

Some of the concerns included threats to the existing relationships within the network that have been created on a high level of trust. Another concern introduced the concept of "reputation currencies" and its potential to better enhance the reputation levels within the network. The reputation is also connected to the parameters of value, which are associated to the quality of performance based on self-assessment: Beginner; Intermediate; Professional including all other talents and skills beyond the formal professional titles, made visible to the community.

The concepts that emerged from both the case studies and interview provided initial inputs for the co-design workshops that followed with the social entrepreneurs from 'I mpactHUB Milan', I taly and 'I mpactHUB King's Cross London'. The series of co-design sessions produced results in the qualities of exchange that are correlated to the creation of value. These were based on the performance typologies that affect the value determination since they are 


\section{THE VALUE OF DESIGN PESE}

11TH EUROPEAN ACADEMY OF DESIGN CONFERENCE

APRIL 22-242015

PARIS DESCARTES UNIVERSITY INSTITUTE OF PSYCHOLOGY

BOULOGNE BILLANCOURT FRANCE

CONFERENCE ORGANIZERS:

PARIS DESCARTES UNIVERSITY PARIS SORBONNE UNIVERSITY PARIS COLLEGE OF ART ISTEC PARIS
Resilient co-creation of value with the consumer. Service design derived forms of value as strategies for subversion.

Telalbasic, Ida characterized as teaching; consulting or co-creating actions between members. Teaching requires repetition where the value lies in the quality and quantity of learned matter and can be a lasting entity. Consulting provides assistance for a specific task and is directed as a one-off intervention. The value created in less valuable in comparison, since those competences will be acquired again at a later stage. There is an underlying question of whether the common learning and sharing of knowledge can be enhance through a structured system as this one or whether the bare recognition of one's competences should be accented, made visible and available for the community. The co-creation stressed the value of mutual creation and therefore creates that value in terms of creative participation on a common project or for a specific goal.

\section{EXPECTED RESULTS}

The final expected result would be both a theoretical model and a service model, considering the user experience of exchange of social capital between individuals, where the value creation mechanism would be based on individual exchange. It will focus on integrating local users, as well as opening up the possibility for trans-community exchange between peers on a global scale. It will include a network of skilled professional that is autonomously sustainable.

If a successful long-term and not only crisis-driven model could be designed, prototyped and globally replicated, based on the debt/credit system and knowledge economy and enormous benefits of access to products and services, then it could enhance economic efficiency and distribute social capital while promoting new forms of entrepreneurship.

The benefits in terms of co-creating value for the consumer are evidently subversive and as such attempt to transform the current monopoly of monocurrencies. The prevailing monoculture in our financial system has proven to lack the individual engagement as well as fostering collaborative behaviours within existing communities. The value creation in alternative economies is considered as a creative response to emerging needs, creating local systems empowered by the group where knowledge transfer, mutual sharing and exchange provides a means for a co-living and co-working phenomena. It is this bottom-up innovation that creates value through participation and this precise value closes the cycle for ontological reference for existence of communities. This co-designed system for products, services and information overthrows the process of individualistic interest-based systems and attempts to establish a society based on trust, sharing and collaborative community building.

\section{THE ROLE OF SERVICE DESIGN}

In the contemporary turbulence of social and economic crisis in society, we are pushed to explore deeper what the emergence of a new kind of design can do today. This new kind of design is a redefined design where socio-economic changes and real world problems are tackled by thinking bigger and applying multidisciplinary knowledge. This emerging culture of design manifests an intersection of design professions, approaches and values and therefore shows a shift from the design traditions of the last century. 


\section{THE VALUE OF DESIGN BESE}

11TH EUROPEAN ACADEMY OF DESIGN CONFERENCE

APRIL 22-242015

PARIS DESCARTES UNIVERSITY INSTITUTE OF PSYCHOLOGY

BOULOGNE BILLANCOURT FRANCE

CONFERENCE ORGANIZERS:

PARIS DESCARTES UNIVERSITY PARIS SORBONNE UNIVERSITY PARIS COLLEGE OF ART ISTEC PARIS
Resilient co-creation of value with the consumer. Service design derived forms of value as strategies for subversion.

Telalbasic, Ida
The nature and purpose of design is approaching problems to make new sense systems by cultural and practical experimentation. Design is an actor who is part of the community it is designing for and developing design strategies capable of transmitting promising proposals into concrete solutions, generated at a social level. This role includes a sensitivity and skill in organizing a community, building scenarios and developing systems of products, services and information to increase its efficiency and accessibility.

There are many good examples where we can identify that services are affecting habits, behaviours and therefore lifestyles, more than products. As a result, services are dematerializing people's lives and creating new value systems and social networks of reciprocal benefits. Some of them illustrate communal benefits, such as co-working, co-using, co-learning etc. where idle capacities are transforming into valuable assets that through design can become easily available and accessible to a vast majority of communities. The conducted codesigned sessions aimed to design scenarios for a collaborative service that is based on the existing trust-based relationships that could strengthen the network, increase the internal collaborations by a providing more structured platform for service offerings and enabling exchanges through the new designed service model for empowering members within the community. Therefore the newly created concept of "co-created empowerment" would act as a mechanism to enable community development through self-help and mutual assistance.

\section{CONCLUSION}

Service design is about the re-designing of interconnections between technology and people as a way to design systems; for example, the redesign of transport, education, economic transactions etc. and this is where the product-servicesystem perspective plays a significant role in determining the key actors and the relevant interactions.

Design takes evidence from other disciplines and merges them synthetically into new scenarios that consider the community and its culture, the context and the emerging issues that have arisen, especially such as one of the contemporary economic crisis. The evidence that design produces is still filtered through borrowing from other scientific fields, such as quantitative and qualitative data research methods that provide some grounds upon which scenarios emerge; design should be classified as an evidence-based design. Design does not search for the truth as science does, but wants to do something better and improve an existing social, economic and environmental complexity.

Service designers enable people through co-design to be involved in the creative process, giving them a shared purpose, creating new narratives and a highly participatory approach where solutions derive from engaged stakeholders and citizens and new business opportunities emerge through the process. The aim is to enable local communities to deliver value by developing progressive visions for economic and social innovation to take place and in this case by exploring how complementary currency systems can truly bring resilient co-created value as a strategy for subversion. 


\section{THE VALUE OF DESIGN CESE}

11TH EUROPEAN ACADEMY OF DESIGN CONFERENCE

APRIL 22-242015

PARIS DESCARTES UNIVERSITY INSTITUTE OF PSYCHOLOGY

BOULOGNE BILLANCOURT FRANCE

CONFERENCE ORGANIZERS:

PARIS DESCARTES UNIVERSITY PARIS SORBONNE UNIVERSITY PARIS COLLEGE OF ART ISTEC PARIS
Resilient co-creation of value with the consumer. Service design derived forms of value as strategies for subversion.

Telalbasic, Ida

\section{REFERENCES}

Adams K. (2005). 'The Sources of Innovation and Creativity'. National Centre on Education and the Economy.

Arrow H., McGrath J. E., Berdahl J. L. (2000). 'Small groups as complex systems: formation, coordination, development and adaption.' Sage Publication Inc.

Bates S. M. (2012). 'The Social Innovation Imperative: Create Winning Products, Services, and Programs that Solve Society's Most Pressing Challenges.' McGrax Hill Companies.

Boyle D. (2011). 'More Than Money.' NEF, Nesta.

Boztepe, S. (2007). 'User Value: Competing Theories and Models.' Middle East Technical University, Ankara, International J ournal of Design.

Burns C., Cottam H., Vanstone C., Winhall J. (2005). 'Red Paper 02Transformation Design.' Design Council.

Cottam H., Leadbeater C. (2004). 'Red paper: Co-creating services.' Design Council UK.

DeMeulenaere S. (2006). 'Annual Report of the Worldwide Database of Complementary Currency Systems Vol.11.'

European Communities (2008). 'Living Labs for user-driven open innovation.' Office for Official Publications of the European Communities.

Florida R. (2011). 'The Rise of the Creative Class.' Perseus Book Group.

Gansky L. (2010). 'The Mesh, why the future of business is sharing.' Penguin Group, New York.

Goldsmith S., Georges G., Burke T.G. (2010). 'The Power of Social Innovation: How Civic Entrepreneurs I gnite Community Networks for Good.' J.W.\&Sons.

Green J. 'Towards a new era of creativity and growth.' Philips Design

Holmlid S. (2009). 'Participative, co-operative, emancipatory: From participatory design to service design.' Dethinking Service, Rethinking Design Nordic Conference.

Jégou, F., Manzini, E. (2008). 'Collaborative services. Social innovation and design for sustainability.' Milan: Edizioni Polidesign.

Kelley T., Littman J. (2001). 'The Art of Innovation: Lessons in Creativity from IDEO.' Random House Inc.

Leadbeater, C. (2008). 'We Think: The Power of Mass Creativity.' Profile Books LTD, London.

Lietaer B. (2002). 'Complementary Currencies in Japan Today: History, Originality and Relevance.' International J ournal of Complimentary Currency Research Vol.8.

Lockwood T. (2009). 'Design Thinking: Integrating Innovation, Customer Experience, and Brand Value.' Design Management Institute.

Manzini E., Jègou F. (2007). 'Creative communities for sustainable lifestyles.' Politecnico di Milano \& Strategic Design Scenarios.

Meroni A., Sangiorgi D. (2011). 'Design for Services.' MPG Books Group, UK. 


\section{THE VALUE OF DESIGN CESE 垔RCH}

11TH EUROPEAN ACADEMY OF DESIGN CONFERENCE

APRIL 22-242015

PARIS DESCARTES UNIVERSITY INSTITUTE OF PSYCHOLOGY

BOULOGNE BILLANCOURT FRANCE

CONFERENCE ORGANIZERS:

PARIS DESCARTES UNIVERSITY PARIS SORBONNE UNIVERSITY PARIS COLLEGE OF ART ISTEC PARIS
Resilient co-creation of value with the consumer. Service design derived forms of value as strategies for subversion.

Telalbasic, Ida
Meroni, A. (2007). 'Creative Communities. People inventing sustainable ways of living.' Edizioni Polidesign, Milano.

Mogensen K. (2006). 'Creative Man-The Future Consumer, Employee and Citizen.' The Copenhagen Institute for Future Studies.

Moritz S. (2005). 'Service Design - A practical access to an evolving field.' University of Applied Science Cologne.

Mulgan G. (2006). 'The process of innovation.' MIT Press.

Mulgan G., Tucker S., Ali R., Sanders B. (2007). 'Social Innovation - What it is, why it matters and how it can be accelerated.' Oxford Said Business School.

Murray R. (2009). 'Danger and Opportunity: Crisis and the new social economy.' NESTA Provocation 09, London.

Murray R., Caulier Grice J., Mulgan G. (2010). 'The open book of Social Innovation.' The Young Foundation.

North P. (2000). 'Complementary currencies and community economic development in an international perspective.' International Conference for Global Responsibility, Stockholm.

Olson M. (1965). 'The Logic of Collective Action: Public Goods and the Theory of Groups.' Harvard Economic Studies.

Osterwalder A., Pigneur Y. (2010). 'Business Model Generation: A Handbook for Visionaries, Game Changers, and Challengers.' John Wiley \& Sons 2010.

Peltomaki A. (2009). 'Living Labs for user-driven open innovation.' European Publications Office.

Pine J., Gilmore J. H. (1999) 'The Experience Economy: Work is Theatre and Every Business a Stage.' Public Service Management Wales. Public Service Delivery with Time Currency - Time Banking.

Saul J. (2011). 'Social Innovation, Inc.: 5 Strategies for Driving Business Growth through Social Change.' J ossey-Bass.

Shirky C. (2008). 'Here Comes Everybody: The Power of Organizing Without Organizations.' Penguin Group.

Steen M. (2009). 'Co-design and Pragmatism.' Paper for the 16th biennial conference of Society for Philosophy and Technology. TNO Information and Communication Technology, Delft, The Netherlands.

Sternberg R. J . (2006). 'The Nature of Creativity.' Lawrence Erlbaum Associates, Inc.

Stickdorn M., Schneider J. (2010). 'This is Service Design Thinking: Basics, Tools, Cases.' BIS Publishers.

Thackara J. (2005). 'In the Bubble. Designing in a complex world.' MIT Press. The Young Foundation (2006). 'Social Silicon Valleys - A manifesto for social innovation. What it is, why it matters and how it can be accelerated?'

Thomke S., Von Hippel E. (2002). 'Customers as Innovators: A New Way to Create Value.' Harvard Business Review.

Thomson M., Koskinen T. (2012). 'Design for Growth and Prosperity.' European Design Innovation Initiative.

Verganti R. (2009). 'Design-Driven Innovation.' Harvard Business Press. 


\section{THE VALUE OF DESIGN PESE}

11TH EUROPEAN ACADEMY OF DESIGN CONFERENCE

APRIL 22-24 2015

PARIS DESCARTES UNIVERSITY INSTITUTE OF PSYCHOLOGY

BOULOGNE BILLANCOURT FRANCE

CONFERENCE ORGANIZERS:

PARIS DESCARTES UNIVERSITY PARIS SORBONNE UNIVERSITY PARIS COLLEGE OF ART ISTEC PARIS
Resilient co-creation of value with the consumer. Service design derived forms of value as strategies for subversion.

Telalbasic, Ida

Von Hippel, E. (1988). 'The Sources of Innovation.' Oxford: Oxford University Press.

Von Hippel, E. (2005). 'Democratizing Innovation.' Cambridge, MA: MIT Press. Wheatley G. (2006). 'Complementary Currency and Quality of LIfe: Social and Economic Capital - Effects on Subjective Well-being.' University of Calgary. 